\title{
Antimicrobial/biocompatible hydrogels dual-reinforced by cellulose as ultra-stretchable and rapid self-healing wound dressing
}

Yajie Zhong ${ }^{a}$, Farzad Seidi ${ }^{a}$ *, Chengcheng Li ${ }^{a}$, Zhangmin Wan ${ }^{a}$, Yongcan Jin ${ }^{a} *$

Junlong Song ${ }^{a}$ and Huining Xiao ${ }^{b, *}$

${ }^{a}$ Jiangsu Co-Innovation Center of Efficient Processing and Utilization of Forest

Resources, and Joint International Research Lab of Lignocellulosic Functional

Materials, Nanjing Forestry University, Nanjing 210037, China

${ }^{\mathrm{b}}$ Department of Chemical Engineering, University of New Brunswick, Fredericton,

NB E3B 5A3, Canada

* Corresponding authors: f_seidi@njfu.edu.cn (F. Seidi); hxiao@unb.ca (H. Xiao); jinyongcan@njfu.edu.cn (Y. Jin). 


\section{Materials and methods}

\section{Oxidation degree of OCMC}

The oxidation degree of OCMC was determined by the hydroxylamine hydrochloride titration method. ${ }^{1}$ Briefly, $0.100 \mathrm{~g}$ of freeze-dried OCMC was dissolved in $25 \mathrm{ml}$ of hydroxylamine hydrochloride $(0.25 \mathrm{M})$ solution containing $0.04 \mathrm{wt} \%$ methyl orange reagent. The mixed solution was stirred for $24 \mathrm{~h}$ at ambient temperature. The amount of aldehyde groups was determined by potentiometric titration of the released hydrochloric acid with $0.1 \mathrm{M} \mathrm{NaOH}$ solution. The oxidation degree of OCMC was calculated according to the equation:

$$
\text { Oxidation degree of } \operatorname{OCMC}(\%)=\frac{(\mathrm{V} \times 0.001 \times \mathrm{C})}{\frac{m}{242}} \times \frac{1}{2} \times 100 \%
$$

Where $\mathrm{V}$ is the consumed volume of $\mathrm{NaOH}$ solution $(\mathrm{ml})$; $\mathrm{C}$ is the concentration of $\mathrm{NaOH}$ solution $(\mathrm{mol} / \mathrm{L}) ; \mathrm{m}$ is the weight of OCMC $(\mathrm{g})$; and 242 is the molecular weight of the repeating unit of OCMC $(\mathrm{g} / \mathrm{mol})$. Three independent samples were measured to get the average value. The results are summarized at Table S2.

\section{Grafting degree of dopamine}

The grafting degree of dopamine was determined by UV-vis spectroscopy. ${ }^{2}$ Gradient dopamine solution was applied in UV-vis spectroscopy to obtain the calibration curve of dopamine.

\section{In vitro drug release test}

It is reported that NEO can react with acetylacetone/formaldehyde solution at mild acidic medium to provide a light yellow product with is detectable by UV spectroscopy ${ }^{3}$. 
The stock solution of acetylacetone/formaldehyde (Ace-ald) was prepared as follow:

A mixture of $0.02 \mathrm{~mol}$ acetic acid, $0.02 \mathrm{~mol}$ boric acid and $0.02 \mathrm{~mol} \mathrm{H}_{3} \mathrm{PO}_{4}$ were dissolved in $90 \mathrm{~mL}$ water and after the $\mathrm{pH}$ of buffer was adjusted at 2.5 with the final volume at $100 \mathrm{~mL}$.

First a calibration curve was prepared by the reaction of various concentrations (5$60 \mathrm{ppm}$ ) of NEO with acetylacetone/formaldehyde stock solution at 1:1 v/v ratio. Then, homogenous solution was closed tightly and heated in boiled water for 20 min to complete the reaction. After cooling down the temperature the absorption of each sample was recorded in the range of $325-525 \mathrm{~nm}$ and the calibration curve with $\mathrm{R}^{2} \approx$ 0.997 was obtained by using the adsorption results at $373 \mathrm{~nm}$ (See Figures S4-S6).

The typical procedure for the release of neomycin from hydrogels is conducted as follow: $0.8 \mathrm{~g}$ of OCMC-DA/PB hydrogels loaded with different amount of neomycin were capsuled into the dialysis bag $(\mathrm{MWCO}=1000 \mathrm{D})$ and immersed into $20 \mathrm{~mL}$ of 0.1 M PBS $(\mathrm{pH}=5.0$ and 7.4$)$ at $25^{\circ} \mathrm{C}$ under mild stirring. $0.5 \mathrm{~mL}$ of release solution was withdrawn at predetermined time intervals, then $0.5 \mathrm{~mL}$ of fresh PBS buffer was supplemented to maintain constant volume. After adjusting the $\mathrm{pH}$ of the sample at $\mathrm{pH}$ 3, the Ace-ald stock solution $(0.5 \mathrm{~mL})$ was added into the released drug sample with the volume ratio of 1:1. The sealed mixed solution was then placed in the boiling water bath for 20 min. Afterwards, the solution with light yellow was cooled down for UV vis test. The Ace-ald solution was tested as blank. All experiments were independently conducted in duplicate.

\section{Antioxidant activity of the hydrogels}


The antioxidant efficiency of hydrogels was evaluated by the method of scavenging the stable 1, 1-diphenyl-2-picrylhydrazyl (DPPH) free radical. ${ }^{4} 100 \mu \mathrm{M}$ DPPH and desired amount of OCMC/PB and OCMC-DA/PB hydrogel samples (10 mg, $20 \mathrm{mg}$ and $50 \mathrm{mg}$ ) were dispersed in $5.0 \mathrm{~mL}$ ethanol. The mixture was stirred and incubated in a dark place for 30 min. Afterwards, the absorption of DPPH mixture was determined by a UV-vis spectrophotometer. The scavenging of DPPH was calculated by the following formula:

$$
\text { DPPH scavenging } \%=\frac{A_{B}-A_{S}}{A_{B}} \times 100
$$

where Ав and As are the absorption of the blank (DPPH + ethanol) and the absorption of the hydrogel samples (DPPH +ethanol +hydrogel) at the wavelength of $517 \mathrm{~nm}$, respectively.

\section{In vitro cytotoxicity assay}

Briefly, the culture medium was prepared containing the Dulbecco's modified Eagle's medium (DMEM) with $1 \%$ NEAA, $1 \%$ sodium pyruvate, $1 \%$ glutamine, and $10 \%(\mathrm{v} /$ v) fetal bovine serum (FBS).

$0.1 \mathrm{~g}$ of the hydrogel was sterilized under UV irradiation for $30 \mathrm{~min}$. Then the hydrogel was immersed into the medium $(5 \mathrm{ml})$ and incubated at $37{ }^{\circ} \mathrm{C}\left(5 \% \mathrm{CO}_{2}\right)$ for $24 \mathrm{~h}$ to prepare the extract solution at the concentration of $20 \mathrm{mg} / \mathrm{ml}$. The extract solution was transferred to the sterilized tube for centrifugation for $5 \mathrm{~min}$ at $1000 \mathrm{rpm}$ and filtered $(0.22 \mu \mathrm{m})$. New medium was added to the filtrate to finally obtain extract solutions at different concentrations $(0.5,1,2,4 \mathrm{mg} / \mathrm{ml})$, respectively.

$100 \mu \mathrm{L}$ NIH3T3 cells $\left(4 \times 10^{4} \mathrm{CFU}\right)$ were seeded in 96 -well plates and incubated at $37{ }^{\circ} \mathrm{C}\left(5 \% \mathrm{CO}_{2}\right)$ for $24 \mathrm{~h}$. After that, the cells were rinsed with $100 \mu \mathrm{L}$ PBS 3 times after 
removing the culture medium. Then cells were incubated with extract solution of the hydrogel at $37{ }^{\circ} \mathrm{C}\left(5 \% \mathrm{CO}_{2}\right)$ for $24 \mathrm{~h}$. The Cells were cultured with the highest concentration of extract solution $(4 \mathrm{mg} / \mathrm{ml})$ for $1 \mathrm{~d}, 3 \mathrm{~d}$ or $5 \mathrm{~d}$. Cells incubated with pure medium were used as a control. Afterwards, the culture medium was replaced by 100 $\mu \mathrm{L}$ fresh medium with $10 \mu \mathrm{L}$ of CCK-8 solution, followed by the incubation at $37{ }^{\circ} \mathrm{C}$ $\left(5 \% \mathrm{CO}_{2}\right)$ for another $2 \mathrm{~h}$, and then optical density (OD) values of the medium were measured at $450 \mathrm{~nm}$ by a microplate reader (TECAN SPARK). The cell viability was calculated according to the Equation:

$$
\text { Cell viability }(\%)=O D s / O D c \times 100
$$

Where $\mathrm{OD}_{\mathrm{s}}$ and $\mathrm{OD}_{\mathrm{c}}$ are for the samples and blank control, respectively. All samples were measured in triplicate.

Live/dead assay. The proliferation viability of NIH3T3 cells was observed by laser scanning confocal microscopy (Olympus, FV1200). Briefly, the cells were seeded with extracts of hydrogels in a 12 -well plate $\left(4 \times 10^{4}\right.$ cell/well $)$ and incubated for one day. The solution of Calcein-AM and PI was then added into each well after cells were rinsed with PBS solution three times. The samples were incubated for $15 \mathrm{~min}$ at $37^{\circ} \mathrm{C}$, followed by a removal of the mixed solution. Afterwards, the samples were washed with PBS solutions three times and observed.

\section{Results and discuss}




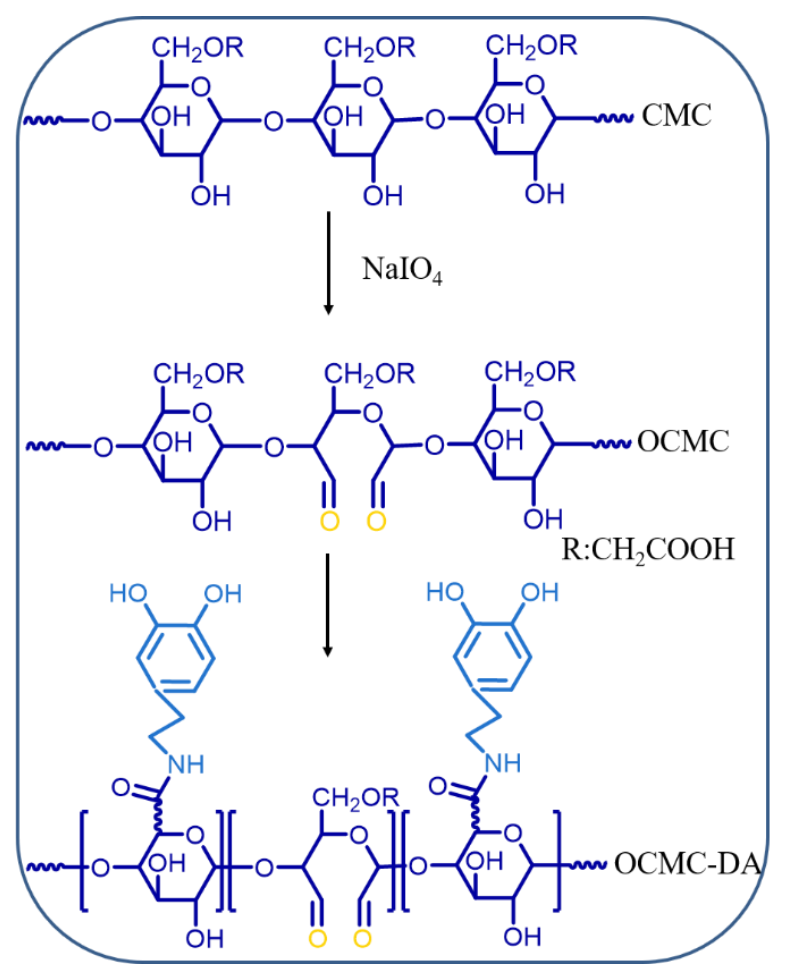

Figure S1. Synthesis of OCMC-DA.

Table S1. The compositions of the hydrogels (concentration of components are $16.7 \mathrm{wt} \%$ for PVA, $2.7 \mathrm{wt} \%$ of OCMC and OCMC-DA, $67 \mathrm{wt} \%$ of glycerol, $0.1 \mathrm{wt} \%$ for CNF, $5 \mathrm{wt} \%$ for borax). Neomycin was dissolved in borax solution before addition to the hydrogel mixture.

\begin{tabular}{lccccccc}
\hline Hydrogels & $\begin{array}{l}\text { PVA } \\
(\mathrm{g})\end{array}$ & $\begin{array}{l}\text { OCMC } \\
(\mathrm{ml})\end{array}$ & $\begin{array}{l}\text { OCMC-DA } \\
(\mathrm{ml})\end{array}$ & $\begin{array}{l}\text { Glycerol } \\
(\mathrm{ml})\end{array}$ & $\begin{array}{l}\text { CNF } \\
(\mathrm{ml})\end{array}$ & $\begin{array}{l}\text { Borax } \\
(\mathrm{ml})\end{array}$ & $\begin{array}{l}\text { Neomycin } \\
(\mathrm{mg})\end{array}$ \\
\hline OCMC/PB1 & 1.5 & 0.8 & - & 0.15 & 2 & 1 & 5 \\
OCMC/PB2 & 1.5 & 1.0 & - & 0.15 & 2 & 1 & 5 \\
OCMC/PB3 & 1.5 & 1.2 & - & 0.15 & 2 & 1 & 5 \\
OCMC-DA/PB1 & 1.5 & - & 0.8 & 0.15 & 2 & 1 & 5 \\
OCMC-DA/PB2 & 1.5 & - & 1.0 & 0.15 & 2 & 1 & 5 \\
OCMC-DA/PB3 & 1.5 & - & 1.2 & 0.15 & 2 & 1 & 5 \\
\hline
\end{tabular}

Table S2. The oxidation degree of OCMC

\begin{tabular}{clllll}
\hline Entry & $\mathrm{m}(\mathrm{g})$ & $\mathrm{C}(\mathrm{mol} / \mathrm{L})$ & $\mathrm{V}(\mathrm{ml})$ & $\begin{array}{l}\text { Oxidation } \\
\text { degree }(\%)\end{array}$ & Average $(\%)$ \\
\hline 1 & 0.100 & 0.1 & 7.30 & $88.3 \%$ & \\
2 & 0.100 & 0.1 & 7.59 & $91.8 \%$ & $90.8 \% \pm 2.1$ \\
3 & 0.100 & 0.1 & 7.62 & $92.2 \%$ & \\
\hline
\end{tabular}




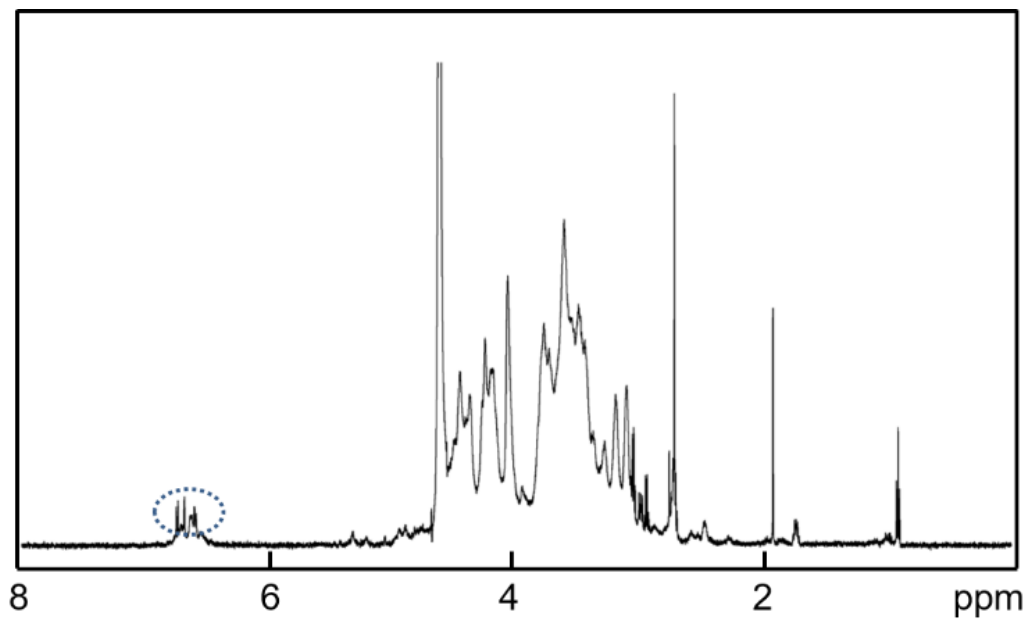

Figure S2. ${ }^{1} \mathrm{H}-\mathrm{NMR}$ spectrum of OCMC-DA.

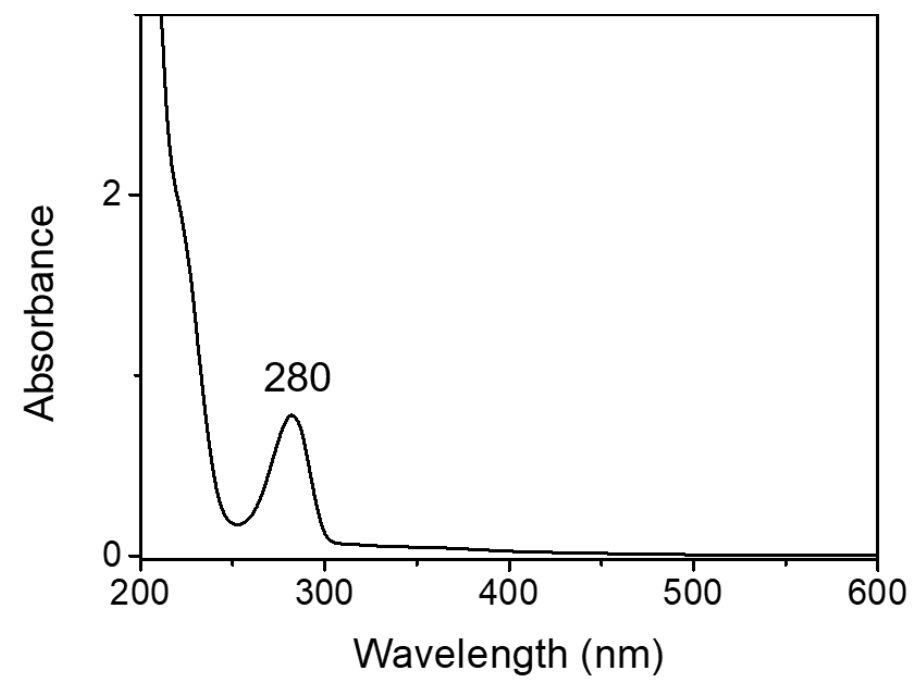

Figure S3. UV-vis spectrum of OCMC-DA

The calibration curve was linear over the range of $0.01 \sim 0.2 \mathrm{mg} / \mathrm{mL}$, and the calibration equation was $\mathrm{y}=12.729 \mathrm{x}+0.0308$ with $\mathrm{R}^{2}$ of 0.9986 . According to the calibration curve of dopamine, the amount of DA moieties can be calculated and the grafting degree of dopamine is $24.4 \%$. 


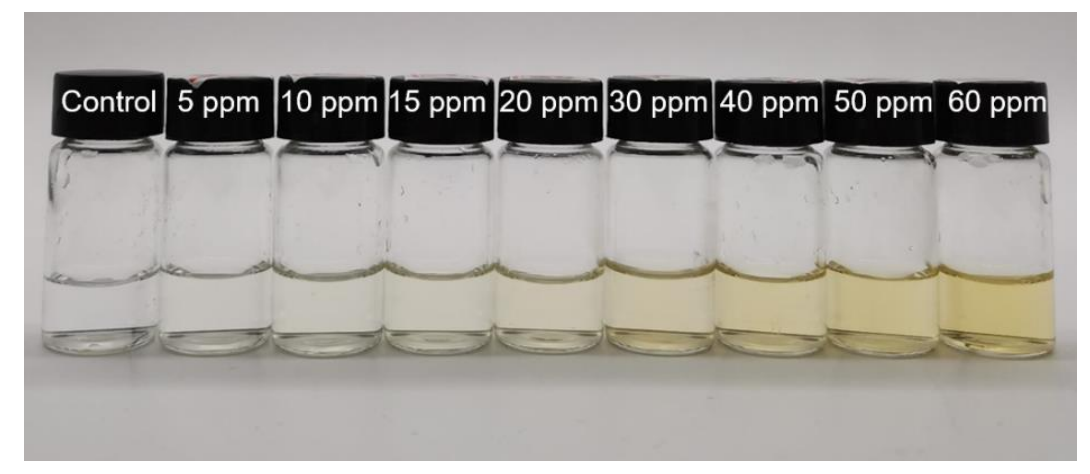

Figure S4. Photograph of Ace-ald/neomycin solution with different amount of neomycin

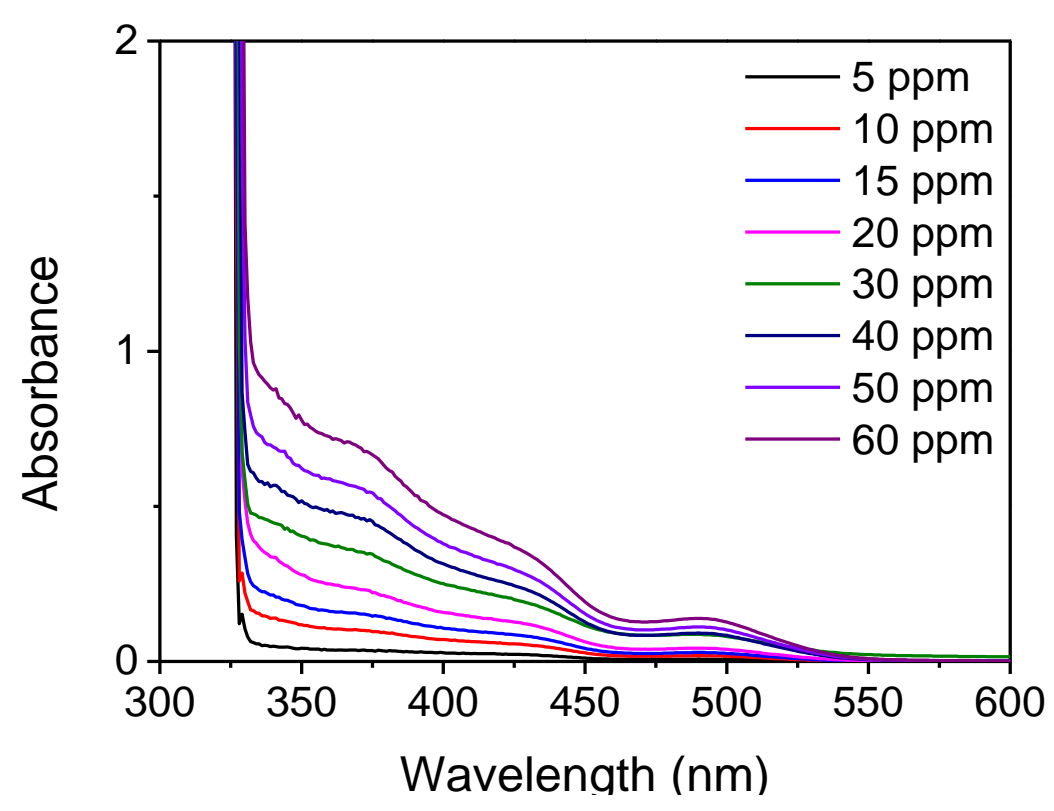

Figure S5 UV-vis spectrum of Ace-ald/neomycin solution 


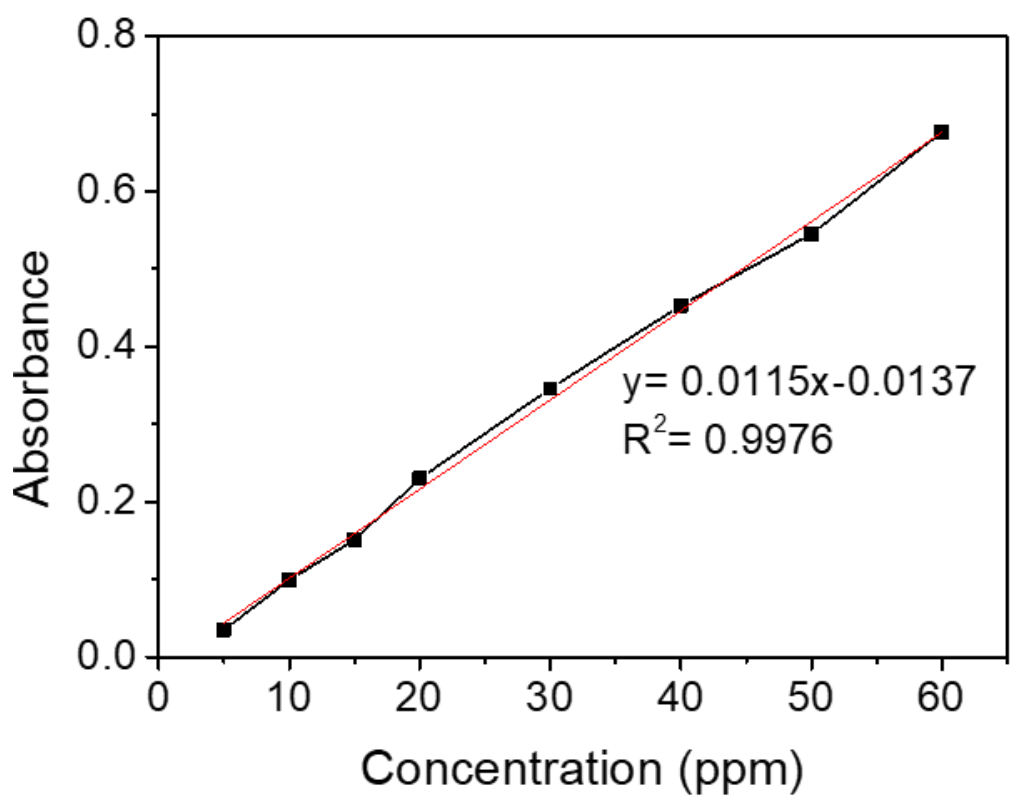

Figure S6 Calibration curve of Ace-ald/neomycin solution in the range of $5 \mathrm{ppm} \sim 60 \mathrm{ppm}$ at 373

$\mathrm{nm}$.
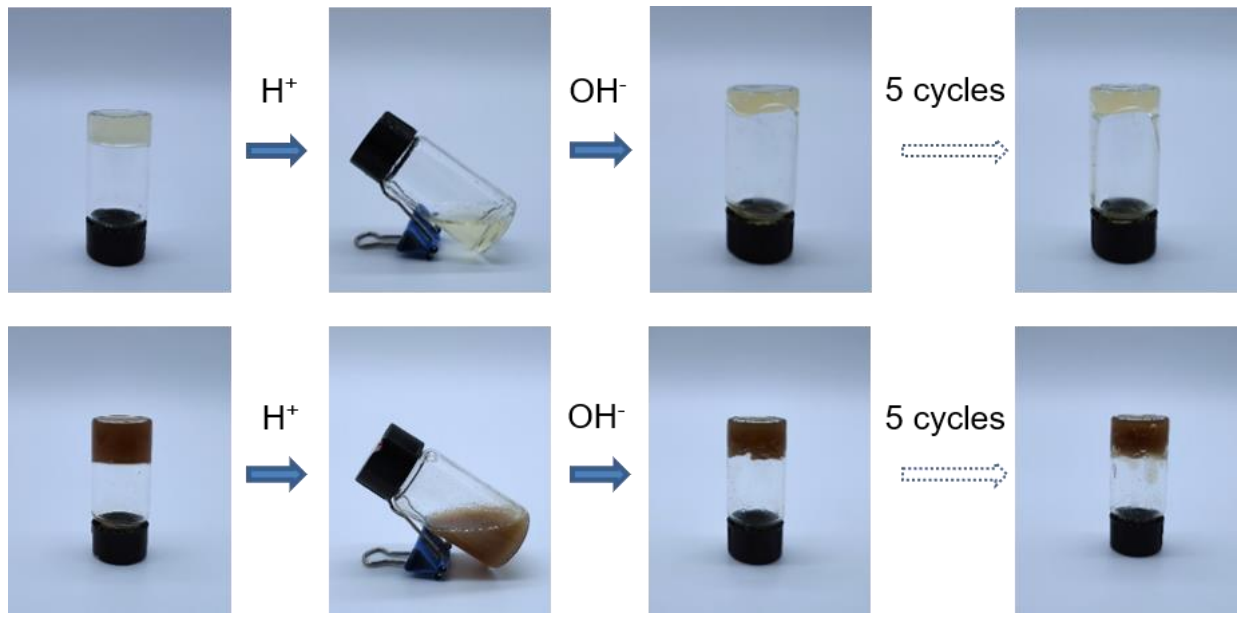

Figure $\mathbf{S} 7$ Gel-sol transitions of OCMC/PB (upper) and OCMC-DA/PB (bottom) hydrogels.

Table S3. The anti-oxidant property of the hydrogels

\begin{tabular}{ccc}
\hline Samples & $\mathrm{m}(\mathrm{mg})$ & DPPH scavenging $(\%)$ \\
\hline OCMC/PB & 10 & 10.5 \\
OCMC/PB & 20 & 13.7 \\
OCMC/PB & 50 & 18.5 \\
OCMC-DA/PB & 10 & 34.7 \\
OCMC-DA/PB & 20 & 39.5 \\
OCMC-DA/PB & 50 & 45.2 \\
\hline
\end{tabular}



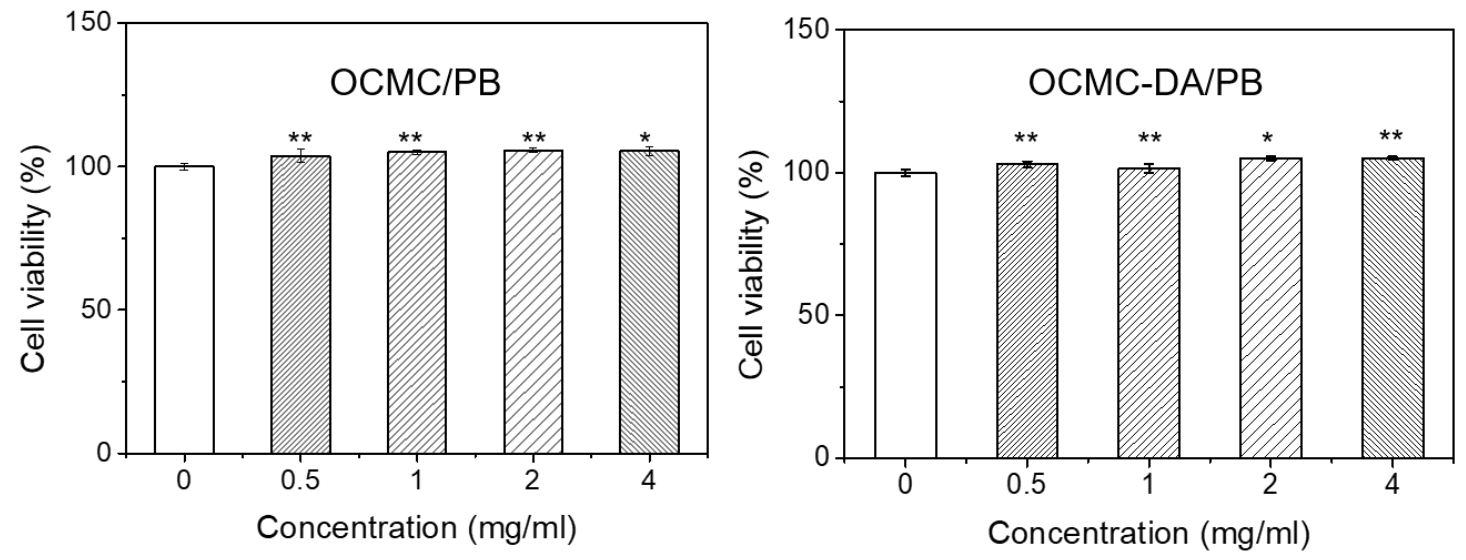

Figure S8. Cell viability when incubated with hydrogel extracts for $24 \mathrm{~h} .{ }^{*} \mathrm{P}<0.05,{ }^{* * \mathrm{P}}<0.01$

\section{References}

1. Chen, T.; Chen, Y.; Rehman, H. U.; Chen, Z.; Yang, Z.; Wang, M.; Li, H.; Liu, H. Ultratough, self-healing, and tissue-adhesive hydrogel for wound dressing. ACS Appl. Mater. Interfaces 2018, 10 (39), 33523-33531.

2. Brubaker, C. E.; Messersmith, P. B. Enzymatically degradable mussel-inspired adhesive hydrogel. Biomacromolecules 2011, 12 (12), 4326-4334.

3. Chen, P.; Qian, L.; Gao, C. Spectrophotometric determination the content of neomycin sulfate eye drops. Jiangsu Pharmaceutical and Clinical Research 2005, 13 (4), 59-60.

4. Liang, Y.; Zhao, X.; Hu, T.; Han, Y.; Guo, B. Mussel-inspired, antibacterial, conductive, antioxidant, injectable composite hydrogel wound dressing to promote the regeneration of infected skin. J. Colloid Interface Sci. 2019, 556, 514-528. 